Check for updates

Cite this: RSC Adv., 2019, 9, 25496

\title{
Effects of chain extender on properties and foaming behavior of polypropylene foam $\uparrow$
}

\begin{abstract}
Do Young Kim, Ji Hun Cha and Kwan Ho Seo (D) *
Polypropylene (PP) foam offers superior thermal and mechanical properties and versatile applications. However, the linear structure of PP hinders the fabrication of a uniform and fine foam, owing to changes in the melt strength with variations in the temperature. The foamability of the material can be improved by fabricating modified PP by introducing long-chain branches by grafting and chain extension reactions, using glycidyl methacrylate (GMA) and adipic acid (AA). Adding 5 phr GMA to PP optimizes the graft ratio. AA as a chain extender forms a long-chain branched structure, as confirmed by the melt flow index, morphology, and thermal and dynamic viscoelastic properties. Variations in foaming characteristics according to the AA content, temperature, volume expansion ratio, and oven residence time have also been observed. An optimal volume expansion ratio of $\sim 14$ is obtained at an AA content of 1.5 phr and foaming for $11 \mathrm{~min}$ at $240{ }^{\circ} \mathrm{C}$.
\end{abstract}

Received 26th June 2019

Accepted 7th August 2019

DOI: $10.1039 / \mathrm{c} 9 \mathrm{ra0} 4824 \mathrm{c}$

rsc.li/rsc-advances

tensile modulus, service temperature and excellent chemical resistance. ${ }^{8-10}$ However, it is difficult to fabricate foams from PP due to its low melt strength, which arises from its linear chain structure and narrow molecular weight distribution. ${ }^{5,6}$ The weak melt strength and high crystallization rate of PP tend to easily rupture the cells because of the low surface tension and narrow processing temperature range used in the foaming process. ${ }^{11}$ Therefore, it is necessary to increase the melt strength of PP to improve its foamability. To this end, researchers have attempted many methods such as blending with other polymers or additives, crosslinking using ionizing radiation, use of chemical agents, and introduction of long-chain branches in the main polymer chain. ${ }^{12-15}$ Among these techniques, the final one improves the melt strength of PP and can be implemented using established equipment.

In this study, PP foam with a high volume expansion ratio (VER) and uniform cells was fabricated by introducing long-chain branch structures for improving the foamability of PP. Grafted PP, made with glycidyl methacrylate (GMA) in the presence of dicumyl peroxide (DCP) and styrene (Sty), was modified with adipic acid (AA), used as a chain extender. The purpose of this study was to obtain an excellent PP foam with a fine cell structure. The mechanism of the grafting and chain extension reaction were investigated by the melt processing, and changes in the PP structure and foamability were evaluated by thermal, rheological, and morphological properties.

\section{Experimental}

Department of Polymer Science and Engineering, Kyungpook National University, Daegu, 41566, Republic of Korea. E-mail: khseo@knu.ac.kr

$\dagger$ Electronic supplementary information (ESI) available. See DOI: $10.1039 / \mathrm{c} 9 \mathrm{ra} 04824 \mathrm{c}$

\subsection{Materials}

Homo-polypropylene (PP, SEETEC H1501, melt flow index: 17 $\mathrm{g} / 10 \mathrm{~min}, 230^{\circ} \mathrm{C}, 2.16 \mathrm{~kg}$ ) was obtained from LG Chem. For 
Table 1 Compositions of grafted PP samples with varied GMA contents

\begin{tabular}{|c|c|c|c|c|c|}
\hline Description & $\mathrm{PP}(\mathrm{wt} \%)$ & GMA (phr) & Sty (phr) & $\mathrm{DCP}^{a}(\mathrm{wt} \%)$ & $\begin{array}{l}\text { Phenolic antioxidant } \\
\text { (phr) }\end{array}$ \\
\hline PP & 100 & 0 & 0 & 0 & 0.3 \\
\hline GPP3 & 100 & 3 & 3 & 1.7 & 0.3 \\
\hline GPP5 & 100 & 5 & 5 & 1.7 & 0.3 \\
\hline GPP7 & 100 & 7 & 7 & 1.7 & 0.3 \\
\hline
\end{tabular}

the grafting reaction, glycidyl methacrylate (GMA) and styrene (Sty) were used as received from JUNSEI Chemical Co. Ltd and Sigma-Aldrich, respectively. Dicumyl peroxide (DCP), used as an initiator, was purchased from Sigma-Aldrich and the chain extender adipic acid (AA) was received from TCI Chemicals for chain extension of the grafted PP. Phenolic and phosphite antioxidant were used for the blends (SONGNOX 1010 and SONGNOX 1680 from SONGWON). Azodicarbonamide (ADCA, KUMYANG, CELLCOM-AC series), which was used as a chemical blowing agent, was decomposed over the temperature range of $\sim 200-205{ }^{\circ} \mathrm{C}$ to form a $280-300 \mathrm{~mL} \mathrm{~g}^{-1}$ gas.

\subsection{Preparation of grafted PP by GMA and modified PP by} AA

For the grafting reaction of PP, a PLASTI-CORDER lab-station with mixer W 50 EHT (BRABENDER, Germany), designed with a counter-rotating twin-screw compounder with a bowl volume of $55 \mathrm{~cm}^{3}$ and roller blades, was used. The grafted PP was produced under a barrel temperature of $170{ }^{\circ} \mathrm{C}$ with a rotation speed of $50 \mathrm{rpm}$ and residence time of $3 \mathrm{~min}$. After the torque was stabilized, a GMA/Sty solution with DCP was added at the same temperature and rotation speed, with an residence time of $5 \mathrm{~min}$. Finally, the phenolic antioxidant was used for terminating the grafting reaction. The components used for grafting PP, with varied GMA contents, are listed in Table 1.

Modified PP by AA were prepared using the grafted PP by 5 phr of GMA at barrel temperature at $170{ }^{\circ} \mathrm{C}$ with a rotation speed of $50 \mathrm{rpm}$ and residence time of $5 \mathrm{~min}$. The components used for modifying the PP samples that used different AA contents are given in Table 2. After pelletizing, the grafted PP samples and modified PP samples were analyzed for grafting and chain extension reactions.

\subsection{Preparation of modified PP foam samples}

Foam samples were fabricated from the modified PP samples with $10 \mathrm{phr}$ ADCA using a PLASTI-CORDER with Mixer W 50 EHT (BRABENDER, Germany) at $170{ }^{\circ} \mathrm{C}$ and $50 \mathrm{rpm}$ over $5 \mathrm{~min}$, as shown in Table 3. The samples were cut into small pieces and compression molding was performed using a Fred S. Carver hot press to obtain circular specimens with diameters of $15 \mathrm{~mm}$ and thicknesses of 2 $\mathrm{mm}$. The molding was carried out at $170{ }^{\circ} \mathrm{C}$ using a preheating time of $4 \mathrm{~min}$ and pressure of 2000 psi for $1 \mathrm{~min}$ and subsequent cooling.

\subsection{Foaming process}

The as-prepared samples were foamed using a hot-air chamber at three different temperatures $\left(220,230\right.$, and $\left.240{ }^{\circ} \mathrm{C}\right)$ at a disk

Table 3 Compositions of $\mathrm{PP}^{a}$ samples modified by AA for foaming process

\begin{tabular}{lccll}
\hline Description & PP (wt\%) & GPP5 (wt\%) & AA (phr) & ADCA (phr) \\
\hline PP-A5 & 100 & 0 & 0 & 5 \\
MPP-A5 & 0 & 100 & 0 & 5 \\
MPP0.5-A5 & 0 & 100 & 0.5 & 5 \\
MPP1.0-A5 & 0 & 100 & 1.0 & 5 \\
MPP1.5-A5 & 0 & 100 & 1.5 & 5 \\
MPP2.0-A5 & 0 & 100 & 2.0 & 5
\end{tabular}

${ }^{a}$ First antioxidant: $0.1 \mathrm{phr}$; second antioxidant: $0.3 \mathrm{phr}$.

Table 2 Compositions of modified PP samples with varied AA contents

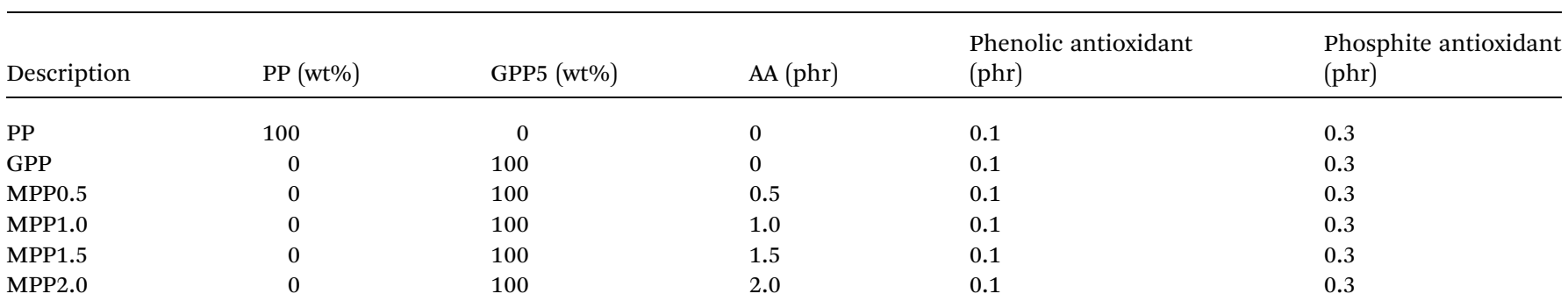




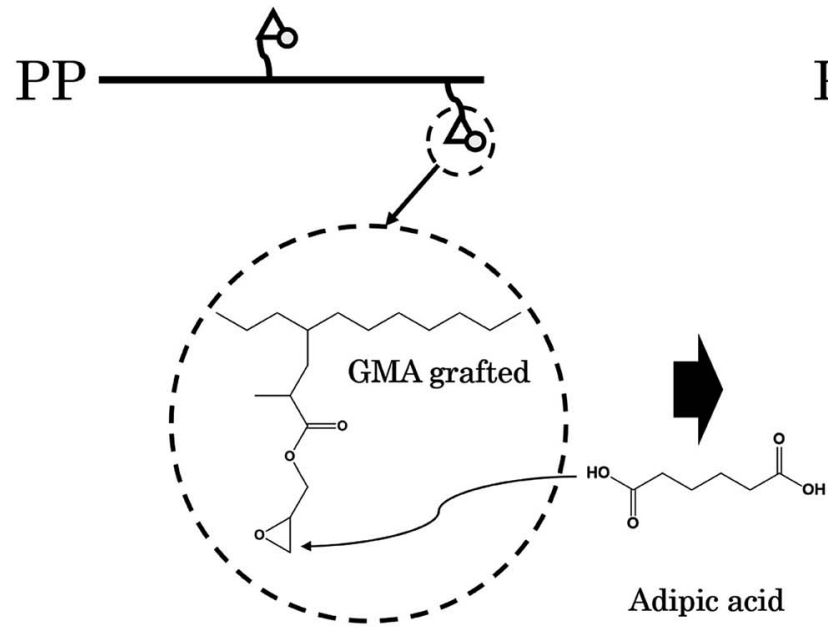

[Grafted PP]

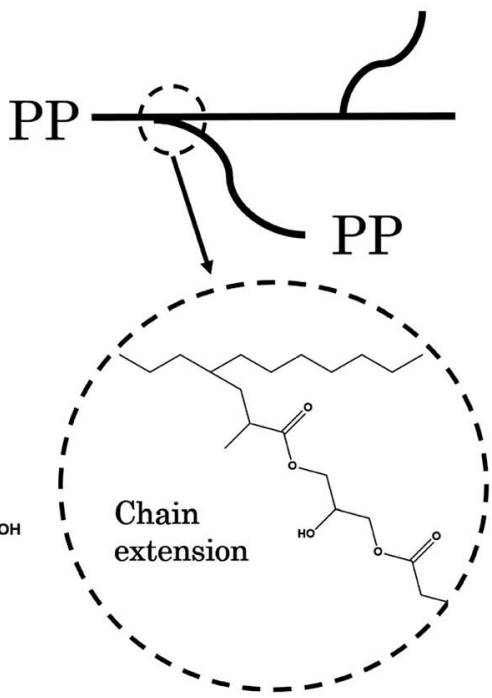

[Modified PP]

Fig. 1 Scheme for modifying PP by chain extension reaction between grafted PP and AA.

rotational speed of $30 \mathrm{rpm}$. The ORTs were $5,7,9,11,13,15$, and $18 \mathrm{~min}$. For all samples, the average values of three different measurements obtained under the same foaming conditions were used.

\subsection{Instrumentation and equipment}

Validation of the grafting and chain extension reactions was performed using Fourier transform infrared spectroscopy
(FT-IR, PerkinElmer, Frontier). The grafted PP and modified $\mathrm{PP}$ were dissolved in xylene at $100{ }^{\circ} \mathrm{C}$ for removing unreacted monomers and various impurities and then precipitated using acetone. The precipitated samples were washed with ethanol and distilled water and dried for $24 \mathrm{~h}$ at $30^{\circ} \mathrm{C}$ under vacuum. The graft ratio of the grafted $\mathrm{PP}$ specimen was compared with the constituent ratio of the PP/GMA mixture using FT-IR absorbance peaks. The components of the PP/ GMA mixture are listed in Table S1.† The mixtures was

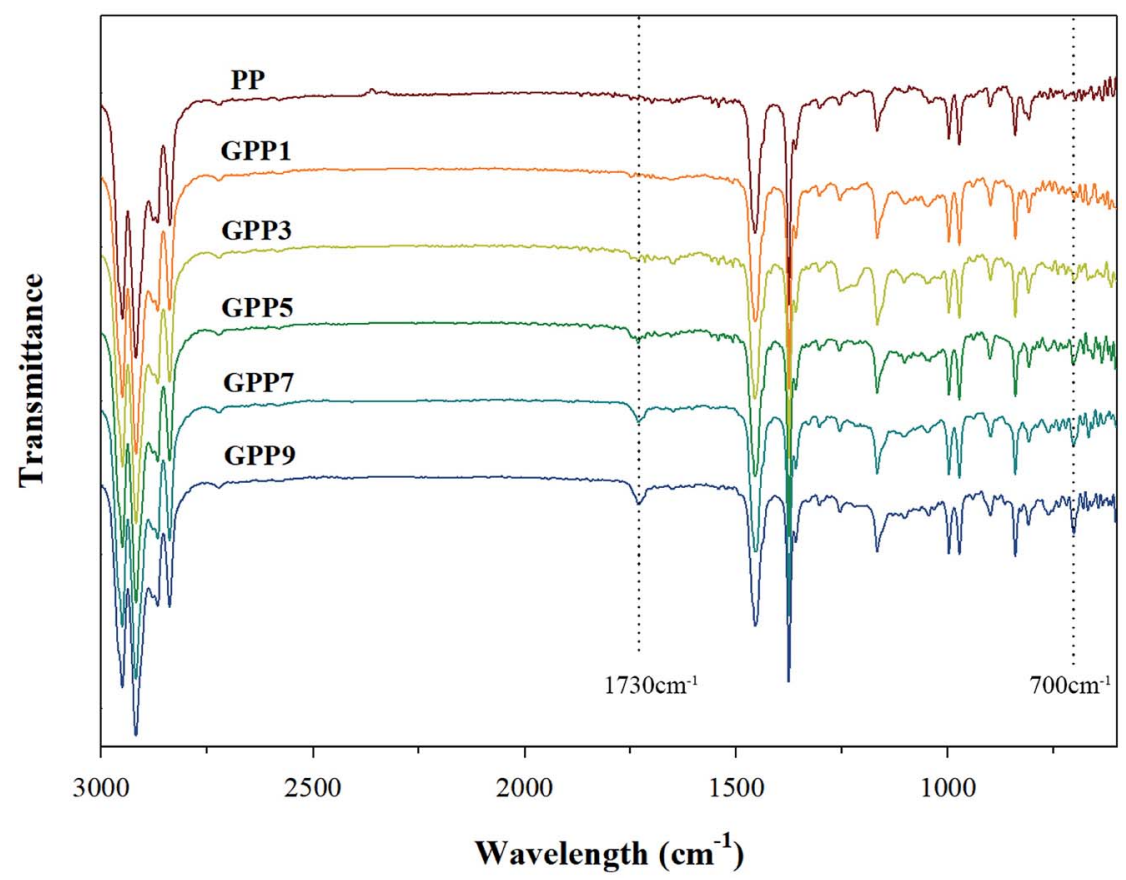

Fig. 2 FT-IR spectra for grafted PP samples with varying GMA contents. 


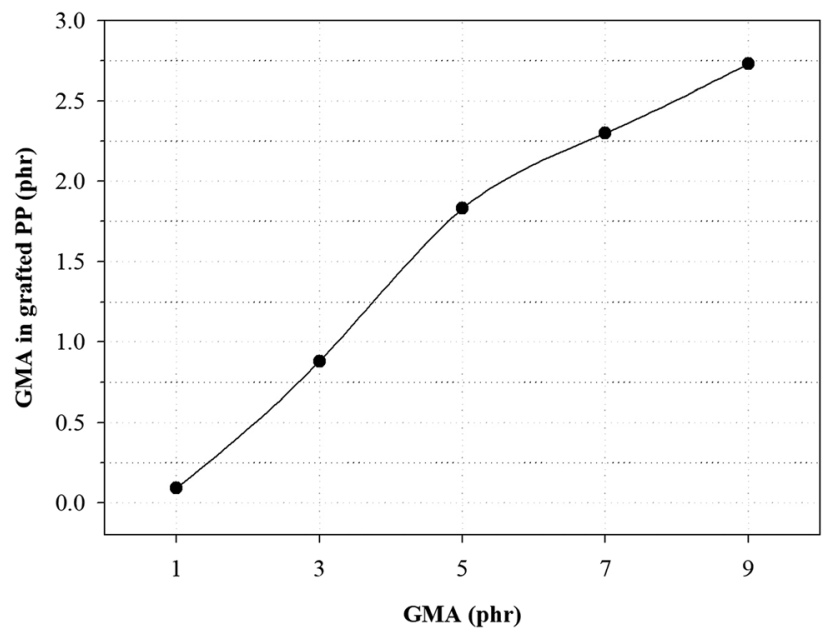

Fig. 3 Variation of GMA contents in grafted PP samples for initial GMA contents.

produced under same conditions without initiator. After pelletizing, the mixtures were analyzed using FT-IR and determined calibration curve using linear regression analysis. As seen in Fig. $\mathbf{S 1}, \dagger$ the graft ratio was calculated as the ratio between constituents as indicated by the absorbance peaks corresponding to the carbonyl stretch of GMA $\left(1730 \mathrm{~cm}^{-1}\right)$ measured before and after the reaction:

Graft ratio $(\%)$

$$
=\frac{\text { GMA content of grafted PP }(\mathrm{phr})}{\text { GMA content of PP/GMA mixture }(\mathrm{phr})} \times 100
$$

Table 4 Variation of graft ratio in grafted PP samples for initial GMA contents

\begin{tabular}{llc}
\hline GMA (phr) & GMA in grafted PP (phr) & Graft ratio (\%) \\
\hline 1.0 & 0.09 & 9 \\
3.0 & 0.88 & 29 \\
5.0 & 1.83 & 37 \\
7.0 & 2.30 & 33 \\
9.0 & 2.73 & 30 \\
\hline
\end{tabular}

The GMA absorbance peak of the samples was corrected with C$\mathrm{CH}_{3}$ absorbance peaks of the PP $\left(2722 \mathrm{~cm}^{-1}\right)$ in order to reflect the actual film thickness.

Dynamic rheological experiments were performed using a strain-controlled AR 2000ex (Ta instrument) with a $13 \mathrm{~mm}$ parallel plate geometry at $180{ }^{\circ} \mathrm{C}$ using a gap size of $1 \mathrm{~mm}$ at 0.01-100 Hz. The samples were formed into sheets by hot pressing at $170{ }^{\circ} \mathrm{C}$. Sample discs with a diameter of $25 \mathrm{~mm}$ and thickness of $2 \mathrm{~mm}$ were prepared.

An MFI tester (MFI-10, DAVENPORT) was used to measure the melt strength of the modified PP at five different temperatures $\left(200,210,220,230\right.$, and $\left.200^{\circ} \mathrm{C}\right)$ with a $2.16 \mathrm{~kg}$ load. All the samples were cut every $30 \mathrm{~s}$, and average values of five measurements were used.

The thermal properties of the modified PP were determined using differential scanning calorimetry (DSC; Q2000, TA instrument) and thermogravimetric analysis (TGA, Q500, TA instrument). For the DSC study, the samples were first heated to $200{ }^{\circ} \mathrm{C}$ at $10^{\circ} \mathrm{C} \mathrm{min}^{-1}$ and kept at that temperature for $1 \mathrm{~min}$ in a nitrogen atmosphere to eliminate previous thermal history. Then, the samples were cooled and heated from 25 to $200^{\circ} \mathrm{C}$ at

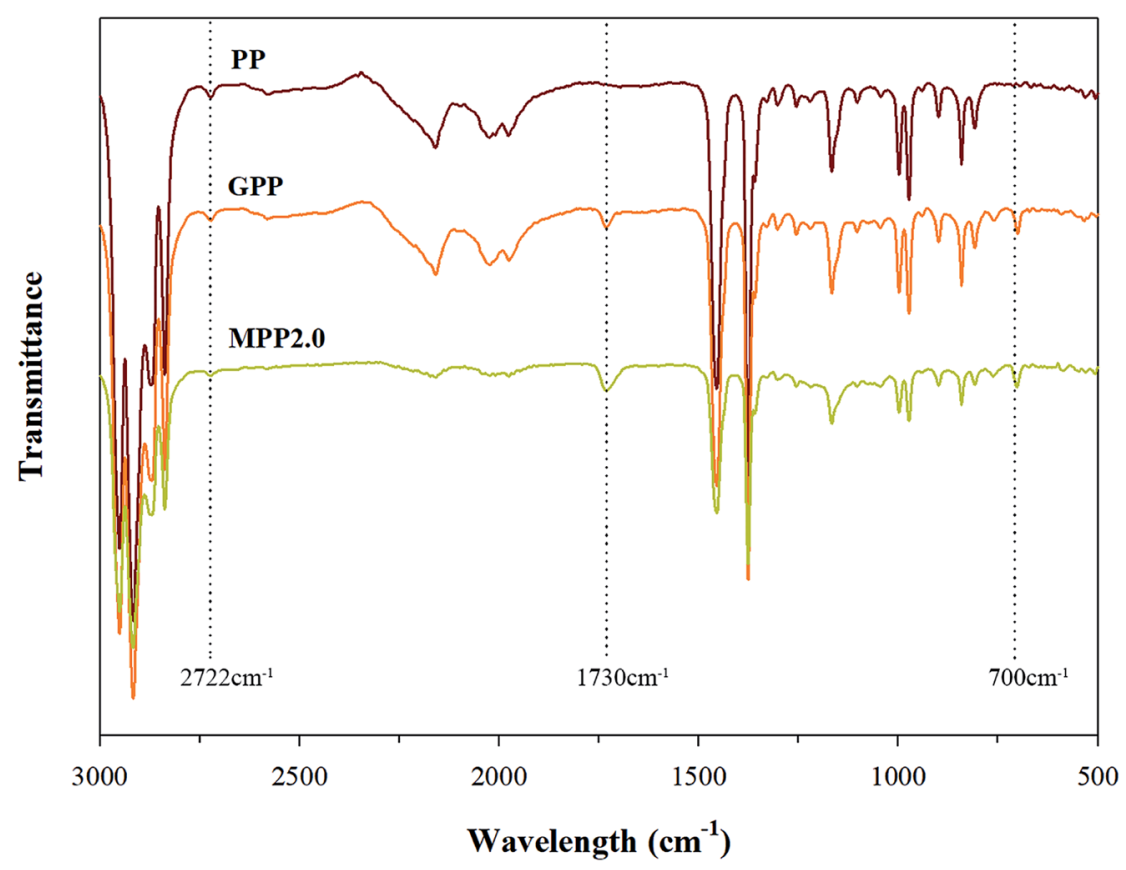

Fig. 4 FT-IR spectra for PP, grafted PP and modified PP samples. 
the rate of $10{ }^{\circ} \mathrm{C} \mathrm{min}^{-1}$. The degree of crystallinity $\left(X_{\mathrm{c}}\right)$ was calculated using eqn (2),

$$
X_{\mathrm{c}}(\%)=\frac{\Delta H_{\mathrm{m}}}{\Delta H_{\mathrm{m}, 100}} \times 100
$$

where $\Delta H_{\mathrm{m}}$ is the heat of melting per unit mass of the crystalline material and $\Delta H_{\mathrm{m}, 100}$ is the heat of melting for the $100 \%$ crystalline random PP $\left(\sim 207 \mathrm{~J} \mathrm{~g}^{-1}\right) \cdot{ }^{16}$ For the TGA analysis, a $7 \pm$ $0.5 \mathrm{mg}$ sample was prepared and the properties were determined from 25 to $600{ }^{\circ} \mathrm{C}$ at a heating rate of $10^{\circ} \mathrm{C} \mathrm{min}{ }^{-1}$ under a nitrogen atmosphere.

The density of the samples was acquired on an electronic densimeter (MD-200S, Mirage) by the water displacement method. The VER was calculated as the ratio between sample densities measured before $\left(\rho_{\mathrm{b}}\right)$ and after foaming $\left(\rho_{\mathrm{a}}\right)$ :

$$
\mathrm{VER}=\frac{\rho_{\mathrm{b}}}{\rho_{\mathrm{a}}}
$$

For all the samples, the average values of three measurements were used.

The cross-sectional morphologies of the modified PP foams were observed using a digital single lens translucent camera (DSLT, Sony a6000) and a micro-lens (Sony SEL30M35).

\section{Results and discussion}

\subsection{Mechanism of grafting and chain extension reactions of PP}

Generally, the radical grafting reaction of $\mathrm{PP}$ is carried out in the melt state using peroxide as an initiator. The radical is generated as the peroxide decomposes under heat, and then react with the hydrogen atoms of the PP backbone to form new radicals in the PP backbone. The radicals in PP are unstable to steric hindrance offered by the methyl groups and therefore may undergo a $\beta$-decomposition reaction, grafting reaction of the monomer and a crosslinking reaction, or partial polymerization of the monomers due to side reactions. ${ }^{17-19}$

Glycidyl methacrylate (GMA) is a bifunctional monomer having both an epoxy group and an acrylic group. The acrylic group of GMA participates in the grafting reaction with other acrylic groups or vinyl groups, but the epoxy group remains in the polymer chain. Thus, it is possible to bond to other polymers or monomers having amine groups, carboxyl groups, and hydroxyl groups. ${ }^{20}$ It is known that the graft ratio is as low as $10-12 \%$ and the molecular weight of PP is greatly reduced when GMA reacts with $\mathrm{PP}$ in the presence of peroxide because it is difficult to react the radical of the PP backbone with GMA due to the large-size of GMA molecular. ${ }^{21,22}$ On the other hand, the graft rate and molecular weight of PP is greatly increased when GMA reacts with PP in the presence of peroxide and Sty because Sty reacts with the radicals of PP, which contributes to the generation of styryl radicals, which are more stable than the radicals in PP. The styryl radical not only stabilizes the $\mathrm{PP}$ radicals by resonance within the styrene benzene rings, but also reacts before the radicals of
$\mathrm{PP} .^{23}$ According to reported studies, the graft efficiency of GMA is best when the ratio of GMA to styrene monomer is $1: 1^{17,21,24}$

Adipic acid (AA) acts as a bifunctional monomer in chain extension, with two carboxyl groups, and can be used to bond
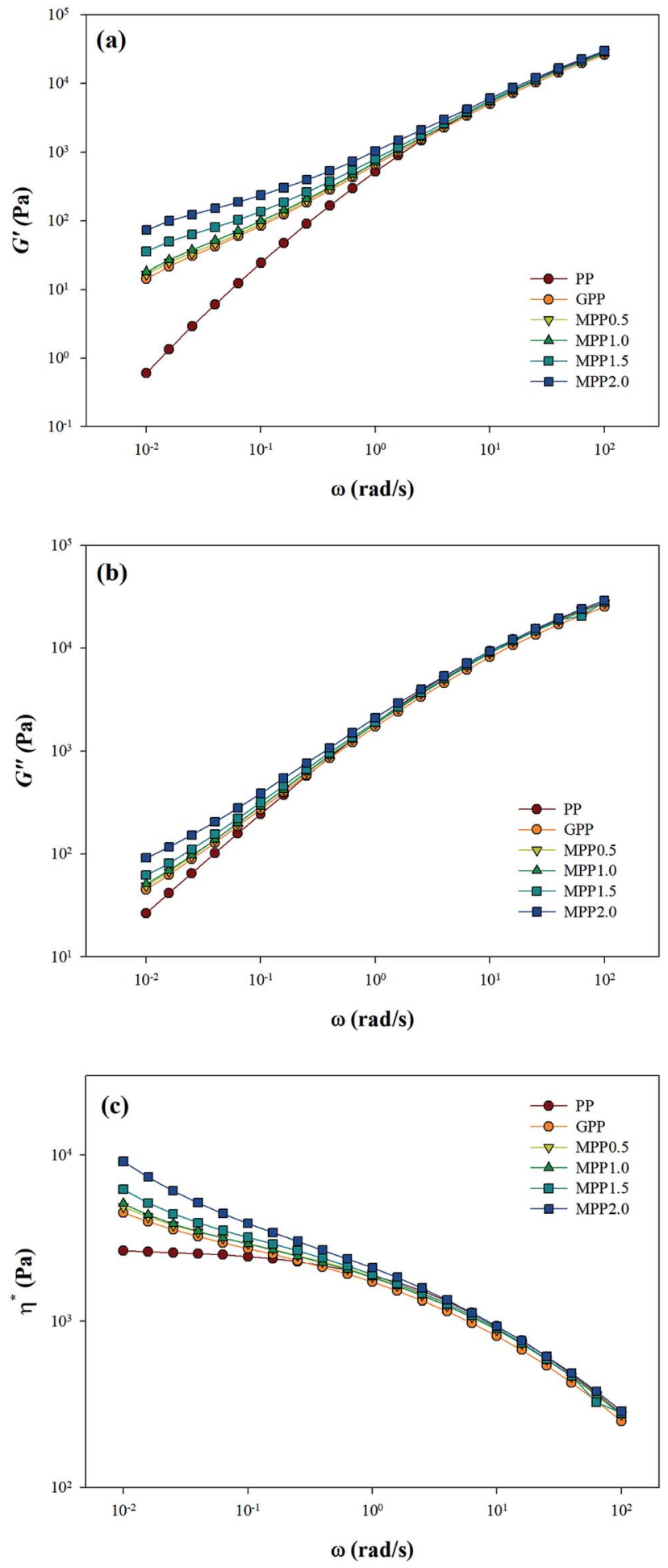

Fig. 5 Linear viscoelastic behavior of PP, grafted PP, and modified PP samples: (a) storage modulus $G^{\prime}$, (b) loss modulus $G^{\prime \prime}$, and (c) complex viscosity, $\eta^{*}$. 
the two polymer chains having an epoxy group and a hydroxyl group. In other words, AA reacts with the epoxy group grafted to the PP chain to form an ester group and forms a bond between the chains. A schematic diagram representing the generation of branched PP through a reaction between grafted PP and AA is shown in Fig. 1.

\subsection{Characterization of grafted PP and modified PP by FT-IR}

Fig. 2 shows characterization of the grafted PP with various GMA contents using FT-IR. The peaks at $1730 \mathrm{~cm}^{-1}$ and $700 \mathrm{~cm}^{-1}$ represent characteristic peaks of GMA and Sty, respectively. The peak at $1730 \mathrm{~cm}^{-1}$ in GMA, assigned to the stretching motion of the carbonyl group $(\mathrm{C}=\mathrm{O})$ in the grafted PP, was compared with that of PP. ${ }^{19}$ The obvious absorption peak at $700 \mathrm{~cm}^{-1}$ signifies the stretching motion of hydrogen atoms in the aromatic ring of styrene. ${ }^{17}$

Fig. 3 and Table 4 show the variation of GMA contents and the graft ratio in the grafted PP with varying initial GMA contents for the determination of the optimal amount of GMA for the grafting reaction. With increasing GMA amount, the graft ratio of the grafted PP is increased because of increase in the grafting reaction with PP. However, the graft ratio on the grafted PP showed that when the GMA content was $5 \mathrm{phr}$, the graft ratio was the highest. As the amount of GMA increased up to $7 \mathrm{phr}$, the probability of polymerization of the GMA monomers increased. ${ }^{25}$ These results indicate that GMA and Sty were successfully grafted onto the PP and the optimal GMA content of the grafted PP was 5 phr.

The FT-IR spectra shown in Fig. 4 confirms that MPP2.0 showed that a chain extension reaction occurred, when its results were compared to those of PP and MPP. The ester group peak close to $1730 \mathrm{~cm}^{-1}$ was assigned to the
Table 5 Degree of shear thinning of PP, grafted PP, and modified PP samples

\begin{tabular}{ll}
\hline Description & Degree of shear thinning \\
\hline PP & 1.08 \\
GPP & 1.64 \\
MPP0.5 & 1.67 \\
MPP1.0 & 1.75 \\
MPP1.5 & 1.95 \\
MPP2.0 & 2.36
\end{tabular}

stretching motion of the carbonyl group $(\mathrm{C}=\mathrm{O})$, owing to the chain extension reaction of the epoxy group in the grafted PP with the carboxyl group of AA. ${ }^{26}$ Thus, changes in the peak was investigated for verifying the chain extension reaction of the modified PP. The absorption peak of ester group was relatively notable in MPP2.0. The $1730 \mathrm{~cm}^{-1}$ peak ratio of the ester group increased, but the ratio shown by the $700 \mathrm{~cm}^{-1}$ peak corresponding to Sty showed no difference. The result indicates that the grafted PP reacted with AA in the chain extension reaction.

\subsection{Rheological properties of modified PP}

The linear viscoelastic behavior of polymers is strongly influenced by the molecular weight distribution, molecular chain length, and topological structure of the polymer. ${ }^{27}$ The linear viscoelastic behavior of a polyolefin polymer is related to the chain structure. To evaluate the changes in the structure occurring because of the chain extension reaction, all samples of the modified PP were analyzed using the van Gurp-Palmen plot, shear viscosities, the Cole-Cole plot,

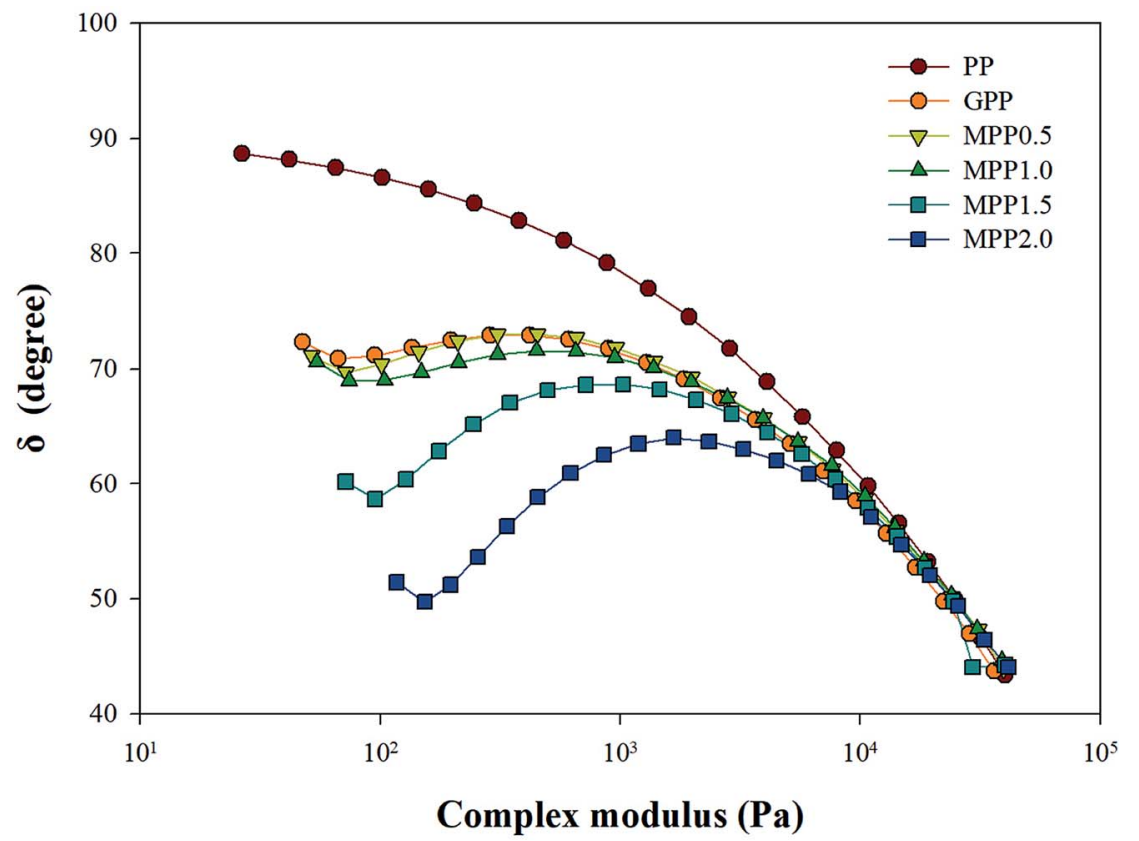

Fig. 6 van Gurp-Palmen plot analysis for PP, grafted PP, and modified PP samples. 


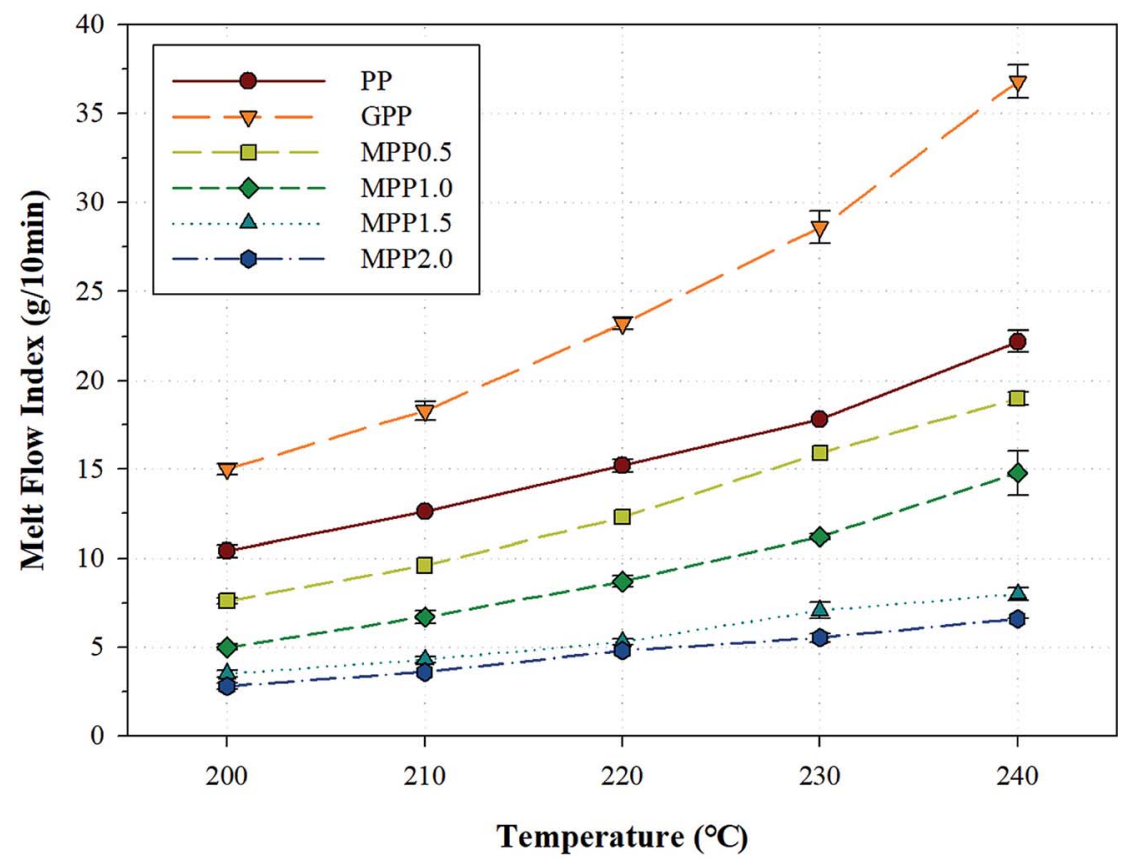

Fig. 7 Melt flow index of PP, grafted PP, and modified PP samples at varying temperatures.

Han plot, and loss factor ( $\tan \delta$ ). Generally, as the structure of polymer changes from linear to branched or partially crosslinked and the molecular weight increases, the elastic property of the polymer improves. ${ }^{28}$ Furthermore, in the case of the linear polymer, when a shear force is applied, the chain of the polymer is elongated partially in the shear direction, whereas the chain of a branch and partially crosslinked polymer is loosened by chain entanglement and arranged in the shear direction. Therefore, the degree of shear thinning is remarkably affected by the relaxation of and decrease in the shear resistance and is close to 1 in the case of a linear structure. ${ }^{29,30}$ The degree of shear thinning was calculated by substituting the complex viscosity in the frequency range of $0.01-0.1 \mathrm{rad} \mathrm{s}^{-1}$ :

$$
\text { Degree of shear thinning }=\frac{\eta_{0.01}^{*}}{\eta_{0.1}^{*}}
$$

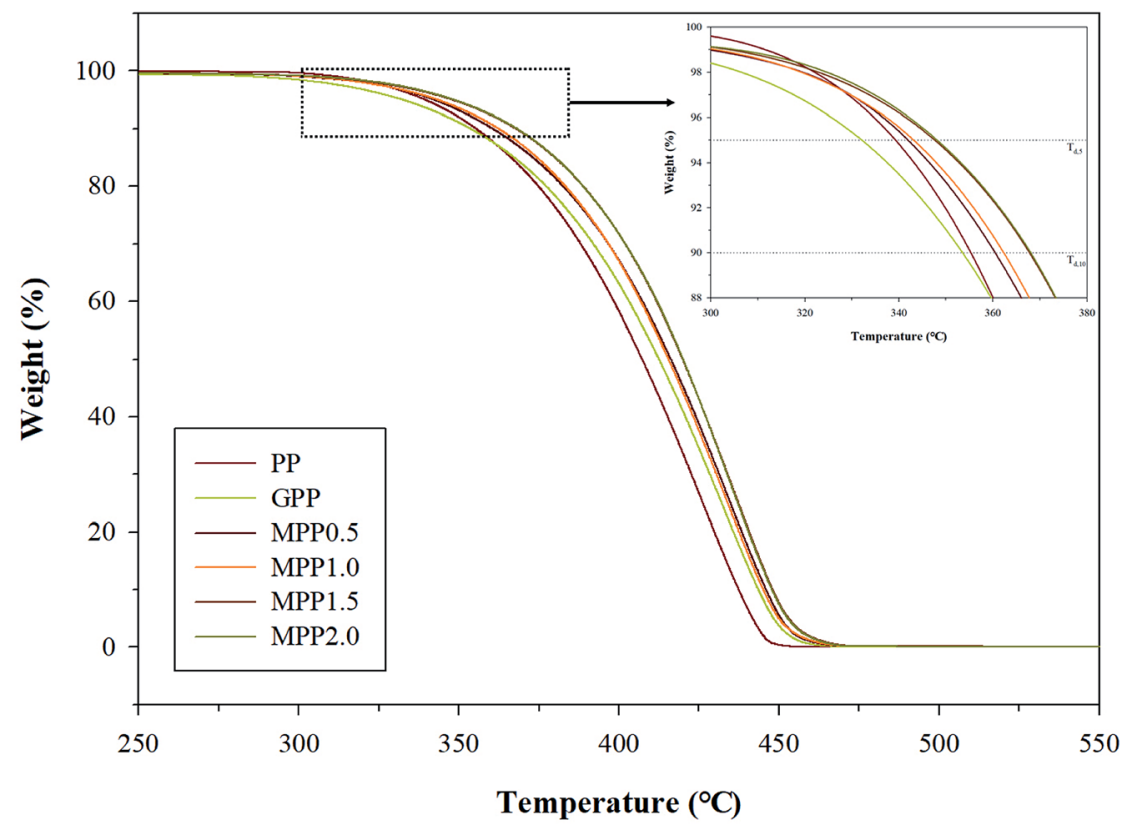

Fig. 8 TGA thermogram of PP, grafted PP, and modified PP samples. 

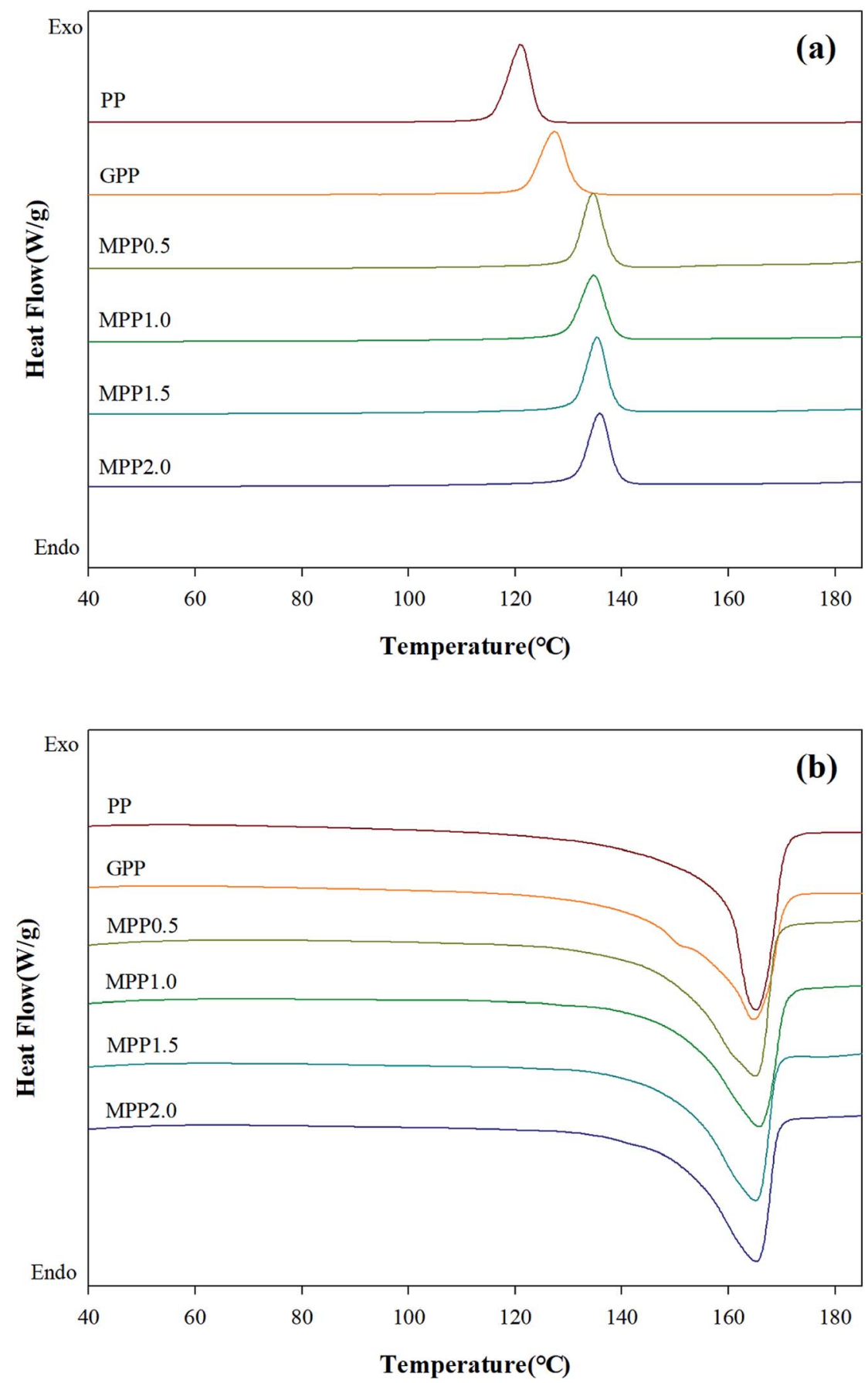

Fig. 9 DSC thermograms of PP, grafted PP, and modified PP samples: (a) non-isothermal cooling curves and (b) heating curves.

In addition, the Cole-Cole plot, Han plot, and loss factor $(\tan \delta)$ demonstrated a similar a change in the viscoelastic behavior, as shown in Fig. S2-S4..$^{29,31}$

As seen in Fig. 5, all the samples showed linear viscoelastic behavior, as demonstrated by the storage modulus $\left(G^{\prime}\right)$, loss modulus $\left(G^{\prime \prime}\right)$, and the complex viscosity $\left(\eta^{*}\right)$. As seen in Fig. 5, it can be observed that the storage modulus $\left(G^{\prime}\right)$, loss modulus $\left(G^{\prime \prime}\right)$, and complex viscosity $\left(\eta^{*}\right)$ of GPP and MPP increased to a greater extent than those of PP. Additionally, the storage and loss moduli increased gradually as the AA content increased; the storage modulus $\left(G^{\prime}\right)$, in particular, increased more than the loss modulus $\left(G^{\prime \prime}\right)$. As for the degree of shear thinning, as shown in Table 5, for PP, it was 1.08, suggesting that it was close to a linear structure. However, with increasing AA content, the degree of shear thinning increased on introducing a branched structure. The van Gurp-Palmen plot for PP, GPP, and MPP is shown in Fig. 6. The phase difference for PP was close to $\frac{\pi}{2}$ in the lowfrequency range whereas it was small for GPP and MPP, 
confirming that the value gradually decreased as the AA content increased. The van Gurp-Palmen plot demonstrates that PP showed the viscosity behavior of a fluid and GPP and MPP exhibited more elastic behavior at $180^{\circ} \mathrm{C}$. This could be attributed to the long-chain branched and partially crosslinked structure formed through grafting and chain extension reactions. ${ }^{27}$ In other words, it was confirmed that longchain branched and partially crosslinked structure were generated in PP by the grafting and chain extension reactions and the elastic properties were improved. ${ }^{27-30,32}$

\subsection{Structural properties of modified PP in terms of melt flow index}

The melt strength of a polymer changes according to various factors such as the temperature, molecular weight, molecular weight distribution, addition of fillers and plasticizers, and structure of the polymer chain. ${ }^{33}$ One method for evaluating the melt flow is observing changes in the melt flow index (MFI). The change in MFI $(\Delta \mathrm{MFI})$ is defined as the difference between MFI values obtained at different temperatures. ${ }^{34,35}$

Fig. 7 shows the MFI results obtained for PP, GPP, and MPP at various temperatures and Table S2 $\uparrow$ shows the $\Delta$ MFI values obtained between 240 and $200{ }^{\circ} \mathrm{C}$. For PP, the MFI increased sharply due to low chain entanglement, which could be attributed to the linear chain structure and high crystallinity in the melt state. Moreover, GPP exhibited higher MFI values than PP, because of the short chains formed by $\beta$-decomposition and unreacted monomers which behaved like plasticizers during the grafting reaction. ${ }^{36}$ On the other hand, as the content of AA increased, the MFI of MPP decreased. The chain extension reaction of AA led to increase in the chain entanglement owing to the high molecular weight and the formation of a long-chain branched and partially crosslinked structure. ${ }^{37}$ This change in the value of MFI could be attributed to not only the chain structure of PP formed by AA, but the effect of the melt strength and temperature range used in the foaming process. In other words, a PP foam could be fabricated by controlling the content of AA.

\subsection{Thermal properties of modified PP determined by TGA and DSC}

We observed the effect of the AA content by thermal analysis using DSC and TGA to confirm the crystallization and thermal stability. The TGA results are shown in Fig. 8 and Table $33, \dagger$ which indicate the $5 \%\left(T_{\mathrm{d}, 5}\right), 10 \%\left(T_{\mathrm{d}, 10}\right)$, and maximum $\left(T_{\mathrm{d}, \max }\right)$ weight loss temperatures. All samples show a single peak in Fig. 8: the $T_{\mathrm{d}, 5}$ and $T_{\mathrm{d}, 10}$ of GPP is 331.5 and $352.9^{\circ} \mathrm{C}$, as shown in Table $\mathrm{S} 3, \dagger$ which are smaller than those of PP. This could be related to early decomposition by $\beta$-decomposition reaction (chain scission) and unreacted monomers. On the other hand, the $T_{\mathrm{d}, 5}$ and $T_{\mathrm{d}, 10}$ of MPP were high for high AA contents. This suggests improved thermal stability due to decreased amounts of unreacted monomers owing to the reacting $\mathrm{AA}$ and GMA and the formation of the partially crosslinked structure. ${ }^{38}$

The DSC thermograms are shown in Fig. 9 and the crystallization temperature $\left(T_{\mathrm{c}}\right)$, melting temperature $\left(T_{\mathrm{m}}\right)$, heat of fusion $\left(\Delta H_{\mathrm{f}}\right)$, and degree of crystallization $\left(X_{\mathrm{c}}\right)$ are listed in Table S4. $\dagger$ The $T_{\mathrm{c}}$ of GPP is higher than that of PP due to the nucleating effect of GMA and the unreacted monomers. In addition, a higher $T_{\mathrm{c}}$ was observed for MPP than for GPP for higher AA contents. This could also be due to the

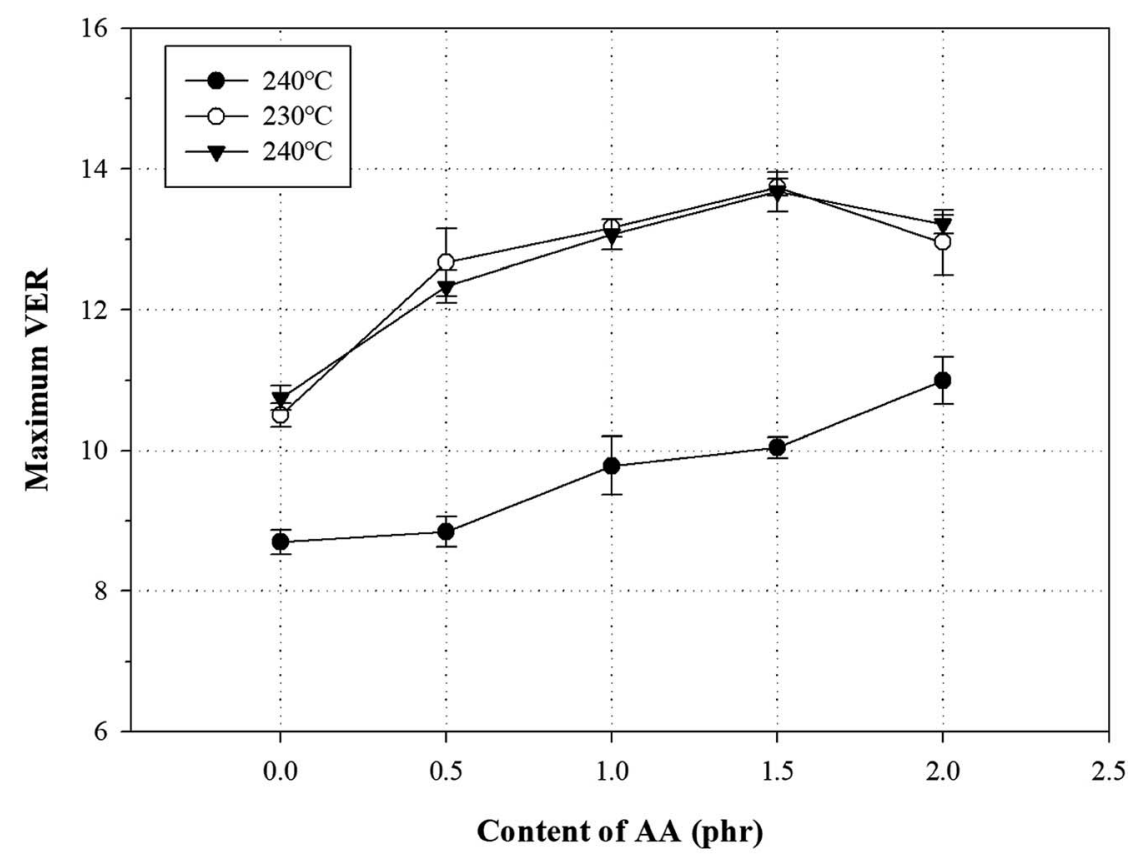

Fig. 10 Variation of VER with AA content in grafted PP and modified PP samples at different temperatures and specific ORT. 
(a)

\section{Time (min)}

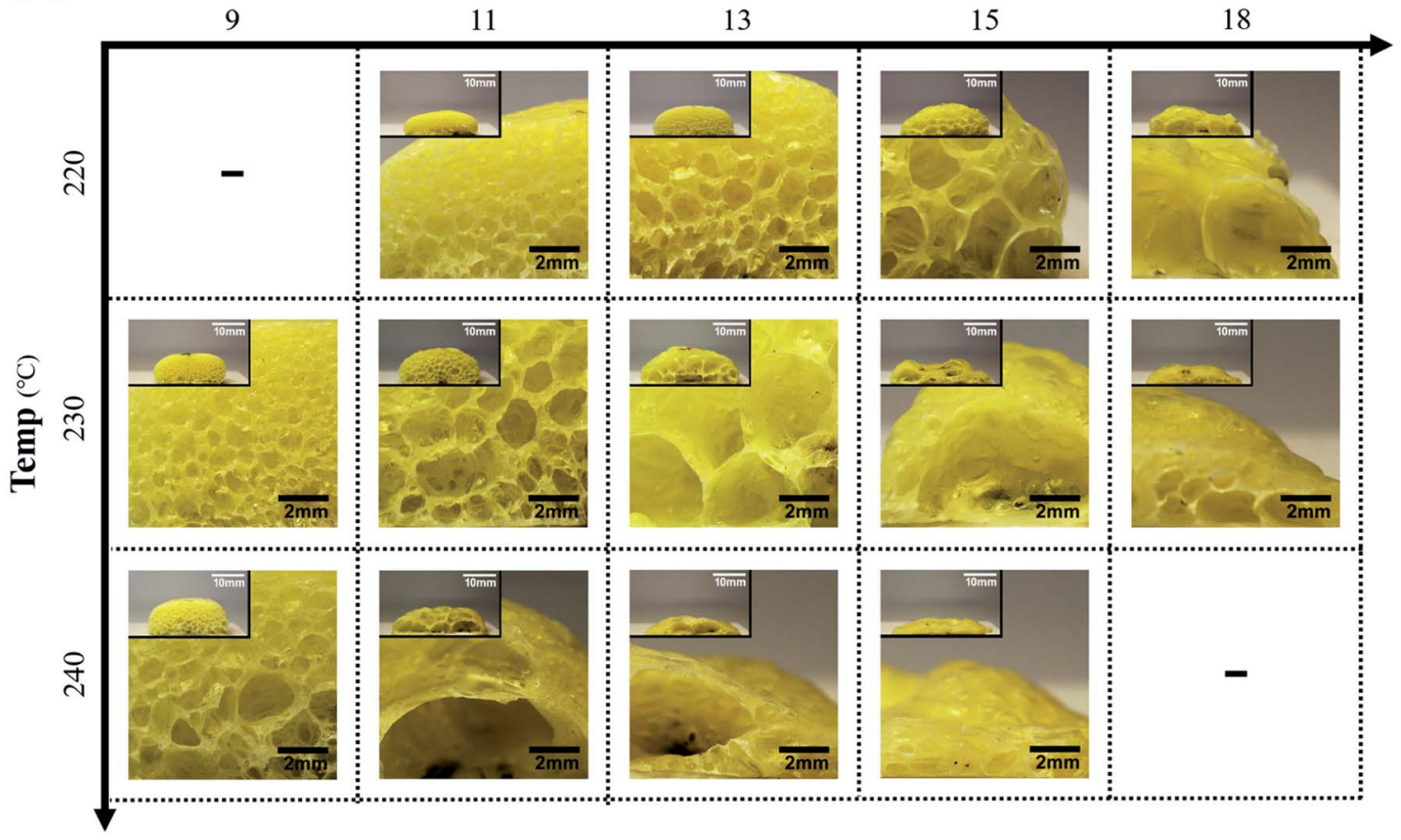

(b)

Time (min)

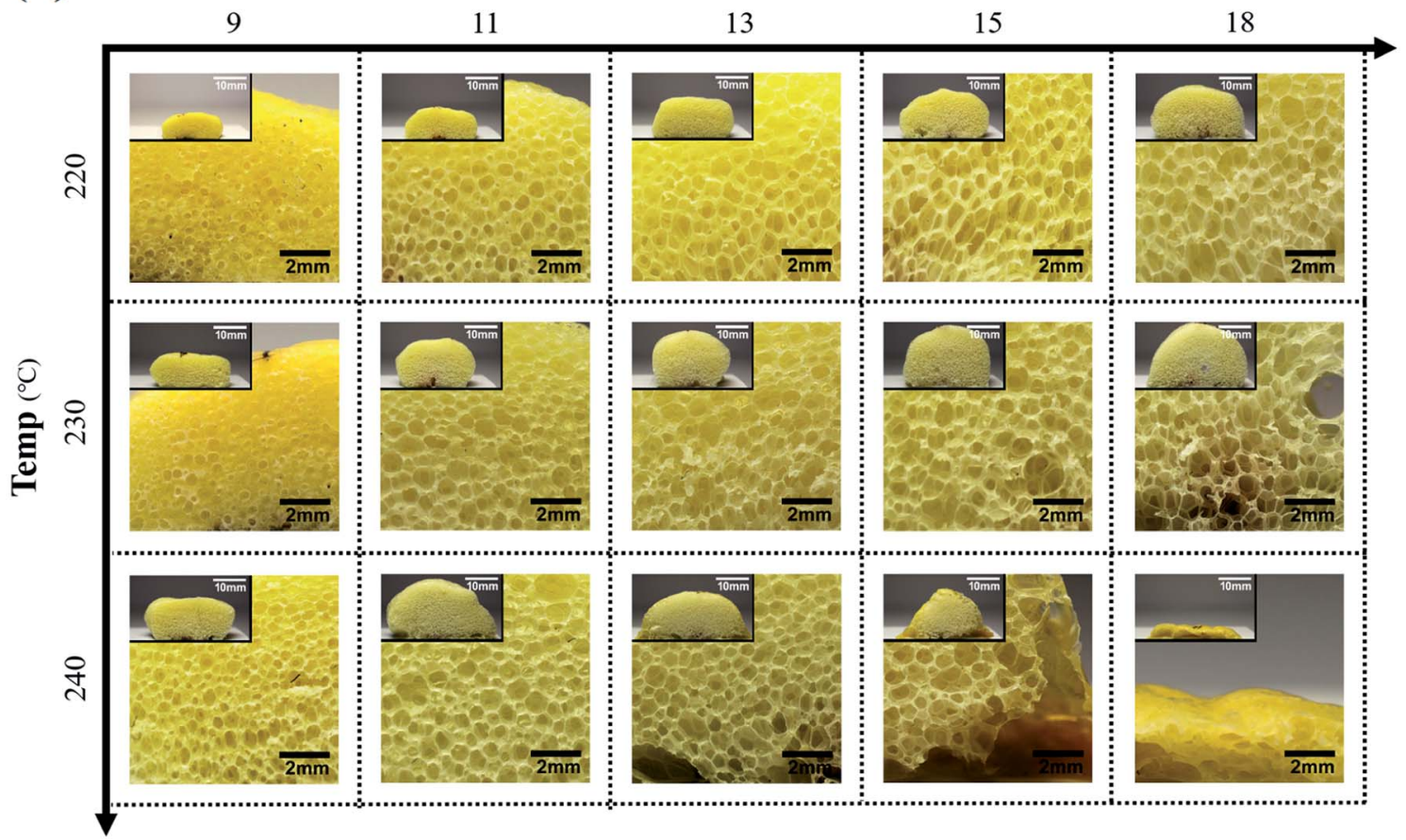

Fig. 11 Cross-sectional microphotographs at different ORTs and temperatures for (a) PP foam and (b) MPP1.5 foam (scale bar: 2 mm; inset scale bar: $10 \mathrm{~mm}$ ).

heterogeneous nucleating effect of the long-chain branched PP. $^{38,39}$ The $T_{\mathrm{m}}$ showed broad and low peaks for GPP and MPP, which could be because of changes in the size of the lamella structure and crystal structure due to restriction of movement of the isotactic PP by the long-chain branch. ${ }^{40}$ The $X_{\mathrm{c}}$ decreased with the addition of AA up to $1.5 \mathrm{phr}$ (MPP1.5), because it interfered with the crystal formation by hindering the chain mobility of PP. ${ }^{41}$ However, when the content of AA 
was $2.0 \mathrm{phr}$, the $X_{\mathrm{c}}$ increased again. It was considered that the unreacted AA affects the nucleating agent. ${ }^{42}$ This result is in good agreement with previous findings on PP reacting with GMA and AA.

\subsection{VER and cross-sectional morphology of modified PP foam}

Generally, a chemical foaming process is used to fabricate foams with a chemical blowing agent and involve the steps of nucleation, growth, and stabilization. ${ }^{43}$ In the nucleation and growth steps, decomposition of the chemical blowing agent leads to an exothermic reaction, which influences the melt strength of the polymer., ${ }^{\mathbf{2 , 4 4} 4 \mathbf{4 6}}$ For this reason, the chemical foaming process is an important factor to optimize conditions such as the foaming temperature and the oven residence time (ORT).

One method to optimize the foaming processing conditions in terms of the AA content is to measure the VER and cross-section morphology. To investigate the effect of the AA content on the foam characteristics, all samples were foamed using varying AA contents, temperatures (220, 230, and $240{ }^{\circ} \mathrm{C}$ ), and ORTs $(5,7,9,11,13,15$, and $18 \mathrm{~min})$ at a fixed content of 5 phr ADCA (Fig. S5 $\dagger$ ). Fig. 10 shows the relationship between the maximum VER and the AA content at different temperatures. The VER at $220{ }^{\circ} \mathrm{C}$ increased with increasing ORT, but the maximum VER values were not reached by the $\mathrm{PP}$ foam, the grafted $\mathrm{PP}$ foam, or the modified $\mathrm{PP}$ foam. The VER at $240{ }^{\circ} \mathrm{C}$ increased rapidly with increasing ORT and showed a decreasing tendency beyond the maximum VER. It is widely known that the surface tension of the cell decreases for a low melt strength of the polymer at high foaming temperatures. In addition, the internal pressure of cell is higher than the surface tension, because the degradation of the blowing agent induces gas generation and pressure per unit time. ${ }^{22,47}$ Therefore, an increase in the foaming temperature could be attributed to the ORT required to reach the maximum VER decreasing. In the case of the PP foam, the maximum VER was observed to be $\sim 6.5$ independent of the process conditions. However, for the grafted PP, the maximum VER increased to $\sim 11$; the addition of 1.5 phr AA improved the maximum VER by $\sim 14$. As mentioned earlier, the melt strength of the modified PP increased owing to the long-chain branched and partially crosslinked structure and held the generated gas inside the foam. However, when 2.0 phr of AA was added, the maximum VER was lower. It could be assumed that the thermal degradation of PP chain is promoted by an increase in the ORT and an excess of AA.

The cross-sectional morphologies at different foaming temperatures and ORTs are shown in Fig. 11. The MPP1.5 foam was compared to the PP foam in terms of the size and shapes of the cell for a fixed ADCA content of 5 phr. For the PP foam shown in Fig. 11(a), the cell size increased with the ORT and foaming temperature and the cells finally ruptured rapidly by releasing the internal gas from the foam. Furthermore, the cells appeared to be non-spherical and were unevenly shaped and fewer in number than in the MPP1.5 foam. MPP1.5 behaved similarly, as shown in Fig. 11(b), but the cell size and shapes were different and the cell ruptured slowly. In addition, the cells in the MPP1.5 foam were more regular, spherical, evenly shaped, and higher in number than in the PP foam. The difference arose from the low melt strength, owing to which the cells combined to lower the free energy of the polymer. ${ }^{22}$ Therefore, the cell size, shapes, and number in the foam were determined by the structure of the polymer at the cell growth and stabilization steps.

\section{Conclusions}

In this study, we discussed the characterization and various properties of modified PP foams with varying contents of AA. To this end, we performed a melt mixing process with grafting and chain extension reactions and achieved uniform foams with fine cells. The chemical reactions occurred in the melt state, and the grafting reaction was confirmed by the graft ratio given by the calibration curve obtained using FT-IR. The chain extension reaction was verified by FT-IR, rheometry, MFI, TGA, and DSC. The modified PP foam was characterized according to the ORT in terms of the VER and the cross-sectional morphology. It was found that a suitable amount of AA on modified PP plays a critical role in the fabrication of the PP foam, as it affects the cell and maximum VER of the foam according to the ORT and foaming temperature.

The FT-IR results showed that GMA and St were successfully grafted onto the PP and the optimal GMA content of the grafted PP was 5 phr. Furthermore, the grafted PP reacted with AA in the chain extension reaction. With increasing AA content, the storage and loss moduli of the modified PP increased gradually, owing to the formation of a long-chain branched and partially crosslinked structure of the PP. It was also confirmed that the modification affected the PP structure using van Gurp-Palmen plot analysis and MFI. TGA and DSC demonstrated that the weight loss temperature and crystallization temperature of the modified PP increased due to the heterogeneous nucleating effect of the long-chain branched PP. Further, effects of the AA content, foaming temperature, and ORT on the VER as well as the cross-sectional morphology of the modified PP foams were investigated. The maximum VER increased significantly except for MPP2.0, which could be attributed to not only the effect of the long-chain branched and partially crosslinked structure of PP, but better capture of the generated gas in the polymer matrix. In conclusion, we fabricated a PP foam using chemical reactions to change the structure and could suggest that the cell size and shapes and quantity of the PP foams were significantly affected by the foaming process. Therefore, we demonstrated a suitable method for improving the foamability of PP, which could find widespread application in research and industry.

\section{Conflicts of interest}

The authors declare that they have no competing interests. 


\section{Acknowledgements}

This research was supported by the National Research Foundation of Korea (NRF) grant funded by the Ministry of Science and ICT for First-Mover Program for Accelerating Disruptive Technology Development (2018M3C1B9069743).

\section{References}

1 C. Maier and T. Calafut, Polypropylene: The Definitive User's Guide and Databook, William Andrew, New York, 1998.

2 S. T. Lee, Foam Extrusion: Principles and Practice, CRC Press, Boca Raton, 2000.

3 Grand view research, Polymer Foam Market Size, Share \& Trends Analysis Report By Type, By Application, By Region, and Segment Forecasts 2018-2025, Grand View Research, Inc., San Francisco, 2018.

4 S. T. Lee, C. B. Park, and N. S. Ramesh, Polymeric Foams: Science and Technology, CRC Press, Boca Raton, 2006.

5 S. K. Goyal, Plast. Eng., 1995, 51, 25.

6 C. B. Park and L. K. Cheung, Polym. Eng. Sci., 1997, 37, 1.

7 S. Li and M. Xiao, Polymer, 2009, 50, 25.

8 M. Plastics, Plastics Handbook, McGraw-Hill, New York, 1994.

9 J. S. Colton, Mater. Manuf. Processes, 1989, 4, 253.

10 J. K. Kocsis, Polypropylene Structure, Blends and Composites: Volume 2 Copolymers and Blends, Springer Netherlands, Dordrecht, 1995.

11 C. Liu, D. Wei, A. Zheng, Y. Li and H. Xiao, J. Appl. Polym. Sci., 2006, 101, 4114.

12 C. Chen and H. Pang, J. Appl. Polym. Sci., 2013, 130, 2.

13 G. J. Nam and J. H. Yoo, J. Appl. Polym. Sci., 2005, 96, 5.

14 J. Ding and W. Ma, J. Mater. Sci., 2013, 48, 6.

15 S. H. Shin and S. Petrov, Radiat. Phys. Chem., 2004, 69, 3.

16 A. K. Ahmed and M. Atiqullah, RSC Adv., 2017, 7, 67.

17 L. Hou and M. Zhao, Express Polym. Lett., 2008, 2, 1.

18 C. Rustal, PhD thesis, University of Stuttgart, 2008.

19 J. G. Kim, Int. Polym. Sci. Technol., 2016, 27, 118.

20 X. Xu and L. Zhag, J. Macromol. Sci., Part B: Phys., 2015, 54, 32.

21 Y. J. Sun, G. H. Hu and M. Lambla, Angew. Makromol. Chem., 1995, 229, 1.
22 N. Liu and C. Xie, Polymer, 1993, 24, 22.

23 S. A. Malaika, Reactive Modifiers for Polymers, Springer Netherlands, Dordrecht, 1997.

24 Y. Rui and S. Chen, Adv. Mater. Res., 2013, 652, 418.

25 L. F. Chen and B. Wong, Polym. Eng. Sci., 1997, 13, 27.

26 Y. Li and S. Jia, Waste Manag., 2018, 76, 172.

27 H. Liu and X. Wang, Cell. Polym., 2015, 34, 2.

28 S. G. Ku and Y. S. Kim, Appl. Chem. Eng., 2017, 28, 1.

29 S. J. Choi and K. H. Yoon, Polymer, 2011, 35, 4.

30 Y. H. Song and K. Hyun, Int. Polym. Sci. Technol., 2017, 28, 5.

31 M. Sugimoto, Y. Suzuki, K. Hyun, K. H. Ahn, T. Ushioda,

A. Nishioka, T. Taniguchi and K. Koyama, Rheol. Acta, 2006, 46, 33.

32 W. Zhao and G. Wu, Polymer, 2012, 51, 7.

33 C. Steve and W. S. Kurt, Prog. Polym. Sci., 2008, 33, 797.

34 K. C. Seavey, Y. A. Liu and N. P. Khare, Ind. Eng. Chem. Res., 2003, 42, 5354.

35 H. C. Lau, S. N. Bhattacharya and G. Field, Int. Polym. Process., 1996, 11, 14.

36 T. P. Russell and L. H. Sperling, Interfacial aspects of multicomponent polymer materials, Plenum Press, New York, 1997.

37 B. Guo and C. M. Chan, J. Appl. Polym. Sci., 1999, 71, 11.

38 H. G. Kim, D. S. Kim and J. H. Kim, J. Text. Sci. Eng., 2010, 47, 117.

39 J. Tian and W. Yu, J. Appl. Polym. Sci., 2007, 104, 6.

40 F. O. M. S. Abreu and M. M. C. Forte, J. Appl. Polym. Sci., 2005, 95, 254.

41 S. H. Tabatabaei, Chem. Eng. Sci., 2009, 64, 16.

42 Y. Liu and C. Zhang, J. Wuhan Univ. Technol., 2013, 28, 5.

43 J. H. Saunders, Handbook of Polymeric Foams and Foam Technology, Book News, Portland, 2004.

44 J. L. Throne, Thermoplastic Foam Extrusion, Hanser Gardner Publications, Ohio, 2004.

45 K. Ashida and K. Iwasaki, Handbook of Plastic Foams, Noyes, New Jersey, 1995.

46 H. Hurnik, Plastics Additives, Hanser, New York, 1990.

47 D. Y. Kim, G. H. Kim, D. Y. Lee and K. H. Seo, J. Appl. Polym. Sci., 2017, 134, 45201. 